\title{
In Memoriam: William (Mickey) Haynes (1943 to 2016)
}

\author{
Daniel G. Friend $^{1}$ • Thomas J. Bruno ${ }^{1}$ - Chris Muzny ${ }^{1}$
}

Received: 9 March 2016 / Accepted: 12 March 2016 / Published online: 4 April 2016

C Springer Science+Business Media New York (Outside the USA) 2016

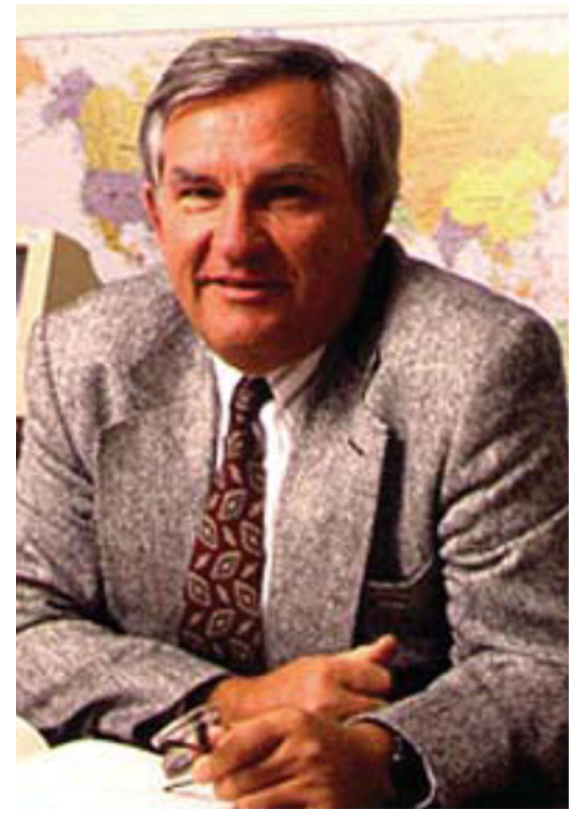

Dr. William (Mickey) Haynes

Contribution of the National Institute of Standards and Technology. Not subject to copyright in the United States.

$凶 \quad$ Daniel G. Friend

daniel.friend@nist.gov

1 Applied Chemicals and Materials Division, National Institute of Standards and Technology, Boulder, CO 80305, USA 
Dr. William (Mickey) Haynes, prominent leader in the thermophysics community and longtime editor of this Journal, died in his home on 25 February 2016 after a year-long struggle with esophageal cancer. Mickey was a long-term mentor, collaborator, and personal friend of the contributors: dozens of leaders and researchers in the field of thermophysics share that relationship.

Mickey was born on 8 February 1943 and raised in Martinsville, a small city in southern Virginia. He grew up as an athlete, and as a star of the Martinsville High School basketball team; his buzzer-beating goal to win the 1961 state championship remains a legend in the city. Mickey was awarded an athletic scholarship to the University of Virginia, and, after a year playing for the UVA basketball team, he accepted an academic scholarship and concentrated on his study of physics. Dr. Haynes earned a B.S. degree in 1965, an M.S. degree in 1967, and his Ph.D. in 1970: all in physics and all at the University of Virginia.

Dr. Haynes' thesis work at UVA, involving measurements of shear strengths of cryogenic methane and argon [1] and the development of a magnetic suspension densimeter for fluids at low temperatures and high pressures [2], foretold a research career based on very careful measurements, creative apparatus development, and absolute dedication to the science from designing a sample holder to the placing of commas in the archival publication. His work at Virginia led to the offer of a National Research Council Postdoctoral Research Associateship in the Cryogenics Division at the National Bureau of Standards (NBS, later re-named to the National Institute of Standards and Technology, NIST).

Mickey began at the NBS Boulder Laboratories in 1970, where he remained throughout his career. He formally retired in 2003, but continued to serve NIST as a Scientist Emeritus and consulting employee until shortly before his death.

While at NBS and NIST, his research work initially continued in cryogenics and densimetry, but evolved to include a number of measurement projects related to characterizing fluids and fluid mixtures through their thermodynamic and transport properties. Mickey was responsible for the development of state-of-the-art apparatus, e.g., a new generation of magnetic suspension densimeter [3] and a torsional crystal viscometer [4]. These instruments were generally used for property measurements at low and high temperatures and at extreme pressures. In 2004, as part of the celebration of the 50th Anniversary of the NIST Boulder Laboratories, three papers of Dr. Haynes were included in the collection of significant papers from the first 50 years of the NIST Boulder Laboratories [5-7]. Dr. Haynes has an enduring reputation as a careful metrologist: his precision property measurements for a number of systems still underpin the analysis of numerous engineering applications.

Dr. Haynes' career advanced at NIST, as he was asked to accept increased responsibilities within the organization. In 1985, Dr. Haynes became Group Leader of the Properties of Fluids Group in the Thermophysics Division at NIST and served in that capacity for ten years. In 1989, he became Deputy Chief of the Thermophysics Division; in 1994 Assistant Director of the NIST Chemical Science and Technology Laboratory; and in 1999, Chief of the Physical and Chemical Properties Division. In these positions, he provided leadership of the fluid properties research program at NIST. He was well known for his vision of a program that integrated experimental measurements and instrument development with theoretical models and data that would 
be of direct use to a user community. These stakeholders included those requiring thermophysical and thermochemical property information for specific technological applications as well as scientists exploring the foundations of matter and thermal sciences.

Within NIST, Dr. Haynes was recognized for his leadership of people and the development of impactful programs. This recognition is supported by his receipt of the U.S. Department of Commerce Silver Medal Award in 2002. Upon his retirement, Dr. Haynes was elected to the NIST Portrait Gallery of Distinguished Scientists, Engineers, and Administrators. These are both very high honors bestowed on the very top echelon of NIST leadership.

Dr. Haynes' framework of an integrated program at NIST was applied to a number of problems. In particular, Mickey led large-scale efforts on natural gas systems, properties of alternative refrigerants, and thermophysical properties of air. In each case, Mickey provided leadership to researchers within NIST and with a number of partners throughout the United States and across the globe. Information developed from these programs has been disseminated in data systems available from NIST, e.g., [8,9] and conventionally published articles, equations, and tables, e.g., [10].

Dr. Haynes' technical work and research leadership were complemented by considerable service to the community. This is typified by his activities related to conferences around the world. He has been active in the European and Asian Thermophysical Properties Conferences, having served on the International Organizing Committee of the former since 1998 (as the sole U.S. member asked to serve), and serving, variously, on Scientific, Program, and International Advisory Committees for the latter at meetings held in China, Japan, and Korea. Indeed, Dr. Haynes was a leader in the movement, decades ago, to coordinate the timing of the North American, European, and Asian Thermophysical Properties Conferences: they remain on a synchronous 3-year rotating schedule. Within the U.S., and as part of his leadership roles within ASME, he participated in the 1977 Symposium on Thermophysical Properties (Gaithersburg, MD), has served on the Symposium organizing committees (ASME K7 and Joint ASME-AIChE Committee) since 1994, chaired/co-chaired/or organized the 13th and 14th Symposia on Thermophysical Properties, and advised the conference chairs at every triennial Symposium from 1991 to the 19th Symposium on Thermophysical Properties held in June of 2015.

In 2014, Dr. Haynes was presented with the Lifetime Achievement Award of the European Conference on Thermophysical Properties at its meeting in Portugal. In 2015, he received the Symposium Award at the 19th Symposium on Thermophysical Properties recognizing long-term and significant service to the Symposium; substantial contributions to the international thermophysical properties community; and leadership in a technical or programmatic area of thermophysics.

As the Editor-in-Chief of the International Journal of Thermophysics from 1997 to 2014, Dr. Haynes not only helped to increase the size and scope of the Journal, but also led the research directions in thermophysics through his guidance of the Editorial Board and rigorous treatment of all submissions to the Journal. He is well known for his keen editor's eye, and publication in Dr. Haynes' journal was a milestone for researchers and engineers throughout the world. The Journal served as the publishing arm of many conferences and workshops, covering thermophysics, thermometry, 
photoacoustics, etc. Dr. Haynes became the Associate Editor of the CRC Handbook of Chemistry and Physics in 2009, and took charge, as Editor-in-Chief for the 2010 edition: he remained Editor-in-Chief through the current 97th edition (2016) [11] and worked toward its completion until a few weeks before his death. This resource is used and cited by many of us who require accurate compilations of information at the basis of our profession. Dr. Haynes instituted new standards of review and analysis of every entry in the Handbook. He has worked with numerous subject matter experts to improve and expand the reference work, and advanced its entry into engineering applications through electronic editions. Additionally, he wielded his editor's pen to improve all of the manuscripts prepared throughout the NIST Boulder campus as Chair of the Boulder Editorial Review Board in the last several months.

It is difficult to enumerate all of Mickey's contributions to thermophysics and the honors bestowed upon him throughout his career. Dr. Haynes served on the Editorial Boards of the Journal of Chemical and Engineering Data, Review of Scientific Instruments, and Cryogenics. He received the Russell B. Scott Memorial Award for Outstanding Paper at the 1981 Cryogenic Engineering Conference, was elected to Fellowship of the American Physical Society in 1999, and was named Fellow of ASME in 2015 .

To add some personal reflections, we note that Mickey Haynes was a man of honor and integrity who treated everyone with respect, regardless of station or stature. He was a friend, a mentor, and an advisor. He was careful, meticulous, and accurate in all of his endeavors. Dr. Haynes often worked seven days per week and was too often "at the lab" until after midnight: he was a dedicated professional.

Outside of NIST, the thermophysics community, and his editorial work, he was an avid sports fan who loved to participate in golf, squash, hiking, biking, and travel. He continued to cheer for his University of Virginia teams to the end, followed collegiate basketball carefully, and applauded the Denver Broncos football (U.S.) team through its 2016 Super Bowl season.

Mickey is survived by his wife of 51 years, Toni Haynes, his son, Mike, a granddaughter, two sisters, and several nieces and nephews. He was pre-deceased in 2013 by his daughter, Jennifer. He is also survived by several generations of younger scientists, for whom he was a superb mentor.

We are aware of a number of other tributes under consideration to honor the memory of Dr. William (Mickey) Haynes. We are pleased to invite correspondence from those who may need additional information about his career.

\section{References}

1. W.M. Haynes, J. Phys. Chem. Solids 32, 791 (1971)

2. W.M. Haynes, J.W. Stewart, Rev. Sci. Instrum. 42, 1142 (1971)

3. W.M. Haynes, Rev. Sci. Instrum. 48, 39 (1977)

4. W.M. Haynes, Physica 76, 1 (1974)

5. W.M. Haynes, M.J. Hiza, N.V. Frederick, Rev. Sci. Instrum. 47, 1237 (1976)

6. W.M. Haynes, R.D. McCarty, M.J. Hiza, Liquefied natural gas densities: Summary of research program at the NBS, Nat. Bur. Stand. (U.S.), Monograph 172 (1983)

7. J.W. Magee, W.M. Haynes, M.J. Hiza, J. Chem. Thermodyn. 29, 1439 (1997) 
8. E.W. Lemmon, M.L. Huber, M.O. McLinden, NIST Standard Reference Database 23: Reference Fluid Thermodynamic and Transport Properties-REFPROP, Version 9.1, National Institute of Standards and Technology, Standard Reference Data Program, Gaithersburg. http://www.nist.gov/srd/nist23.cfm (2013)

9. NIST Chemistry WebBook, NIST Standard Reference Database Number 69, ed. by P.J. Linstrom and W.G. Mallard. http://webbook.nist.gov

10. W.M. Haynes, E.W. Lemmon, D.G. Friend, R.T Jacobsen, Thermodynamic properties of air at pressures to $2000 \mathrm{MPa}$, in Proceedings International Conference High Pressure Science and Technology (AIRAPT-16 \& HPCJ-38), Kyoto, Japan (1998), pp. 1171-1176

11. W.M. Haynes, CRC Handbook of Chemistry and Physics, 96th edn, ed. by D.R. Lide, T.J. Bruno (CRC Press, Boca Raton, FL 2015) [latest edition available] 